\title{
New $50 \mathrm{~Hz}$ Superconducting Power Supply for a $2 \mathrm{kA}$ DC Magnet
}

\author{
Oleg A. Shevchenko, Herman H. J. ten Kate, Erik J.G. Krooshoop \\ Applied Superconductivity Centre, University of Twente, \\ P.O. Box 217, 7500 AE Enschede, The Netherlands \\ Nick V. Markovsky \\ Institute of Electrodynamics, Ukrainian AS, \\ Peremoga Prospect 56, Kiev 57, 252680 The Ukraine
}

\begin{abstract}
A new superconducting power supply able to operate directly from the mains voltage at a frequency of 50$60 \mathrm{~Hz}$ is under development in our institutes. It will be applied to power a separator magnet for iron ore recycling. The supply consists of a full wave superconducting converter, a 'cold' protection system, and control and measuring units. Typical design values of the device are: output current of 1-2 kA, voltage of 1-0.5 V; input current of $7 \mathrm{~A}$, voltage of $220 \mathrm{~V}$ and frequency of $50 \mathrm{~Hz}$; an efficiency better than $96 \%$. The high current part of the supply finally will be placed in the same cryostat as the separator magnet. The basic concept of the device is presented in the paper.
\end{abstract}

\section{INTRODUCTION}

Superconducting (SC) magnets have some unique requirements that call for novel design configurations of their power supplies [1], [2]. Comparison of the semiconductor and superconductor based supplies shows that a combination of both can improve important parameters of the powering system for a separator magnet such as an efficiency and external characteristics.

The investigations reported here are part of a development program to improve the operating performance of $50-60 \mathrm{~Hz}$ superconducting rectifiers and to realise specific applications in combination with SC magnet systems. In particular, it is planned to built a 1-2 kA superconducting supply for a powering system of a separator magnet which is under development now [ 3].

The separation effect causes a decrease of the energy stored in the magnet when operating in persistent mode. This loss is determined by the magnetic interaction of the stationary magnet and the fluid to be separated.

It results in a permanent current degradation of about $1 \%$ per hour in the typical operating regime of the separator. This effect makes a direct application of removable current leads and a persistent mode switch unsuitable. An improvement would be the introduction of a device that can make up this loss efficiently in order to maintain the magnet current at a constant level.

Manuscript received September 20,1993. This work is supported by the Netherlands Scientific Organisation (NWO) and by the Ukrainian State Committee for Science and Technology.

\section{PRINCIPLES OF OPERATION}

A powering system for the superconducting magnet of the separator requires two different power supplies. A main power supply (based on semiconducting elements) will be used to ramp the magnet current from zero to the nominal value. As the separator works continuously, it is expected, that this procedure will take place approximately once a month. The superconducting power supply will be used to control the magnet current (around $10 \%$ of the nominal value) during nominal performance of the separator. The SC supply is a relatively complex and new device, so aspects related to the protection and reliability of the electrical system of the magnet must be considered carefully.

\section{A. Powering system of the magnet.}

In Fig. 1 the basic electrical scheme of the powering system of the separator magnet is presented. Here $\mathbf{L}$ is the superconducting magnet including a passive protection system. The presence of this system by which the magnet energy is dumped inside the cryostat is essential in order to avoid high current protection leads.

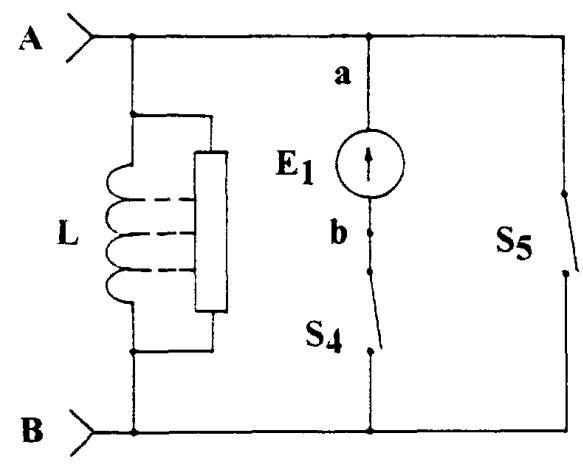

Fig. 1. Basic scheme of the magnet powering system. 
In Fig. $1 \mathbf{A}$ and $\mathbf{B}$ are the contacts to connect the magnet to the 1-2 $\mathrm{kA}$ main power supply. It includes a $24 \mathrm{~V}$ semiconducting power supply and removable current leads (both are not shown). A main superconducting switch $S_{4}$ is used to provide a persistent current mode.

Here $\mathbf{E}_{\mathbf{1}}$ represents the SC power supply, $\mathbf{S}_{\mathbf{5}}$ represents a 'cold' mechanical switch which is applied here for active protection of the converter circuit $\mathbf{E}_{1}$ and of the switch $\mathbf{S}_{\mathbf{4}}$. While powering the magnet by the main power supply, switches $S_{4}$ and $S_{5}$ are opened. During the control of the magnet current by the $S C$ power supply, switch $S_{4}$ is closed and $S_{5}$ is opened. In the persistent current mode switches are closed.

In the case of a quench in the circuit of $\mathbf{E}_{1}$ or in switch $S_{4}$, the low resistance of switch $S_{5}(\leq 10 \mu \Omega)$ enables a recovery of the supply and the switch almost without affecting the operation of the magnet. This makes the electrical powering system of the magnet safe and reliable.

All components shown in the scheme, can be placed in the same cryostat as the magnet.

\section{B. Superconducting power supply.}

An electrical scheme of the SC power supply is presented in Fig. 2.

It consists of a power control unit $\mathrm{CU}$ located at room temperature and connected to the mains, and a superconducting converter, placed in the cryostat and connected to the magnet. The converter consists of a SC transformer (represented in the Figure by a primary coil $\mathbf{L}_{p}$ and secondary coils $\mathbf{L}_{1}, \mathbf{L}_{2}$ ), both repetitive superconducting switches $S_{1}$ and $S_{2}$, a persistent current switch $S_{3}$ and some other components. Passive protection of the supply is represented by 'cold' diode units $\mathbf{D}_{1}$ and $\mathbf{D}_{2}$. Points $\mathbf{a}, \mathbf{b}$ correspond to Fig. 1.

In general, the operation of the SC power supply is rather similar to the operation of the usual power supply based on thyristors and led by the mains.

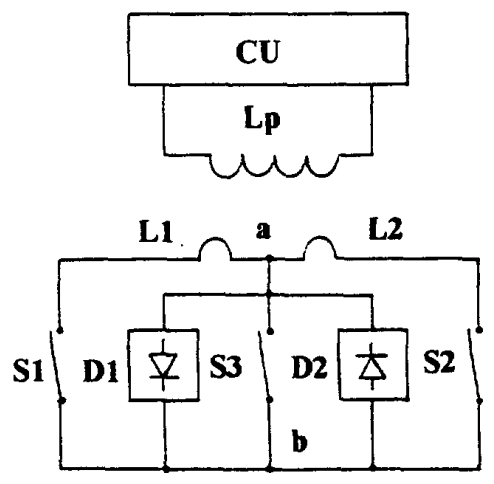

Fig. 2. Basic scheme of the SC power supply.
During the powering process, the transformed and rectified input voltage is applied to the magnet. As a result, both the input and output currents are increasing versus time (signs of the currents and voltages are the same).

In the inversion mode, the output voltage and current are opposite. As a result, the amplitudes of the input and output currents are decreasing versus time.

Further details about principles, theory of the operation, and basic design of this type of superconducting converters are presented in references [4] and [5].

\section{DESIGN AND CONSTRUCTION}

The requirements that have to be met for this particular power supply are:

- two-quadrant operation;

- output current of 1-2 kA;

- average output voltage of $\pm(1-0.5) \mathrm{V}$;

- input voltage of $220 \mathrm{~V}$ at $50 \mathrm{~Hz}$;

- input current below $8 \mathrm{~A}$;

- an efficiency better than $96 \%$;

- liquid helium operation temperature.

The control pulses for the repetitive switches should have a momentary power $<25 \mathrm{~W}$ and a duration $<1 \mathrm{~ms}$.

The supply volume must not exceed 30 and 25 litres for the "warm" and "cold" parts respectively.

The supply must have a separate protection system to prevent damage during fault operation. Moreover, the operation and control should be easy and reliable.

\section{A. The "warm" part.}

The power control unit of the supply is realised within the mentioned limitations. It enables four-quadrant operation for the 'cold' part and can transfer $10 \mathrm{~A}$ at $500 \mathrm{~V}$ in both directions. The direct power switch of the device is based on two thyristors, the shunting switch is transistor based. Both power switches operate in a switching mode, which provides a higher efficiency.

To drive the power unit, a PC-based control system "Keithley 500" is used. This enables to test various algorithms in order to select the most suitable for this application.

\section{B. The "cold" part.}

Commutation inductance. A $50 \mathrm{mH}, 10$ A copper inductance is connected in series with the SC transformer primary coil in order to limit a current rate in the circuits of the SC converter during the commutation stages. It is placed at liquid nitrogen temperature in order to reduce the active resistance. Fig. 3 gives an impression of the superconducting part of the system prepared for a test. 


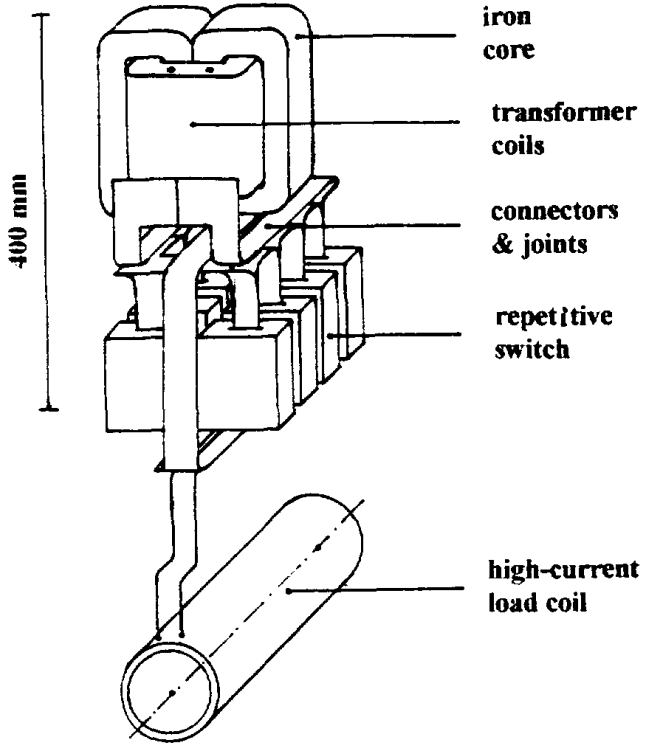

Fig. 3. Schematic view of the SC converter.

The conductors. The conductors used to build the SC converter components, are specified in Table 1. The losses in the repetitive switches are dominant. This enables a wider choice for the conductors used in other components of the converter.

The transformer. To provide an average output voltage of $1 \mathrm{~V}$ during powering the magnet, each secondary coil of the transformer must generate a $2 \mathrm{~V}$ amplitude (see below). A cold non-saturated iron core SC transformer is selected to reduce the input voltage of $310 \mathrm{~V}$ amplitude. It is based on two strip wound cut C-cores of type $2 *$ SG-127/51 [6]. The transformer coils are wet-wound using STYCAST $2850 \mathrm{FT}$, with $0.5 \mathrm{~mm}$ channels to provide a good cooling.

Assuming a coupling coefficient of 0.999 , the other important parameters of the transformer can be derived. They are listed in Table 2 .

The switches. Fast response thermally activated SC switches are used as the repetitive elements in the converter.

TABLE 1

SPECIFICATION OF THE CONDUCTORS

\begin{tabular}{lccc}
\hline Applied in & Material & Bare size & \# Filaments \\
\hline primary coil & $\mathrm{NbTi} / \mathrm{CuNi}$ & $\varnothing 0.225 \mathrm{~mm}$ & 574 \\
secondary circuit & $\mathrm{Nb}_{3} \mathrm{Sn} / \mathrm{Cu}$ & $5 * 0.2 \mathrm{~mm}$ & tape \\
switches $\mathrm{S}_{1}-\mathrm{S}_{3}$ & $\mathrm{NbTi}$ & $25 * 0.01 \mathrm{~mm}$ & foil \\
magnet & $\mathrm{NbTi} / \mathrm{Cu}$ & $2.5 * 1 \mathrm{~mm}$ & 36 \\
\hline
\end{tabular}

TABLE 2

SPBCIFICATTON OF THE SC TRANSFORMER

\begin{tabular}{lcc}
\hline Parameter & $1 \mathrm{kA}$ & $2 \mathrm{kA}$ \\
\hline Primary self-inductance $[\mathrm{H}]$ & 65.7 & 65.7 \\
Secondary self-induct., each $[\mathrm{mH}]$ & 2.974 & 0.6476 \\
Primary to secondary turns ratio & $1115 / 15 / 2$ & $1115 / 7 / 2$ \\
Coupling coefficient & 0.999 & 0.9992 \\
\hline
\end{tabular}

Their construction is similar to those developed earlier for an operating current of $250 \mathrm{~A}$ [7]. Both the operating current and voltage are $\sim 5$ times higher in the present case. To scale the device, a new switch unit is designed. It consists of four sections, connected in series in the case of $1 \mathrm{kA}$ output current (see Fig. 3) and two in series, two in parallel in the case of $2 \mathrm{kA}$. Each section contains a $100 \mathrm{~mm}$ long bifilarly wound foil (see Table 1) as a gate element and two discrete heater elements to trigger the gate. Other parameters of the switches are presented in Table 3.

The parameters of the persistent current switch $S_{3}$ (for $1 \mathrm{kA}$ ) are: max. off-resistance of $1.4 \Omega$, min. propagation current of $1 \mathrm{~A}$, gate time constant of $0.5 \mathrm{~s}$, and heater resistance of $20 \Omega$.

The magnet. The separator magnet is not yet available for the tests. To test the SC power supply, a small superconducting solenoid is prepared with an inductance of $10 \mathrm{mH}$, and a maximum current of $1 \mathrm{kA}$.

The protection system:

- a 'cold' mechanical switch $S_{5}$ [8] provides an active protection and a reversible behaviour of any SC component (except the magnet) when a quench occurs;

- silicon based 'cold' diodes assembled in units $\mathbf{D}_{1}$ and $\mathbf{D}_{2}$ protect the supply from damage when switch $\mathbf{S}_{\mathbf{5}}$ is open;

- each section of the repetitive switches is individually protected by 'cold' Schottky diodes of type BYS 28-45 in order to limit voltage spikes caused by commutation errors.

TABLE 3

SPECIFICATION OF THE SC REPETITIVE SWITCHES

\begin{tabular}{|c|c|c|}
\hline Parameter & $1 \mathrm{kA}$ & $2 \mathrm{kA}$ \\
\hline Max off-resistance, $[\Omega]$ & 0.8 & 0.2 \\
\hline Min propagation current, [A] & 6 & 12 \\
\hline Max. AC current (at $60 \mathrm{~Hz}$ ), [A] & 1250 & 2500 \\
\hline Gate time constant, [ms] & 1.5 & 1.5 \\
\hline Resistance of the heater, $[\Omega]$ & 15 & 15 \\
\hline Min. triggering voltage, $[\mathrm{V}]$ & 25 & 25 \\
\hline
\end{tabular}




\section{RESULTS AND DISCUSSION}

Various numerical simulations and small scale experiments are performed in order to specify the operation of the separate components of the power supply. The results obtained so far are in a good agreement with the theory [4], [5] and [9].

On the base of these results the output characteristic of the $1 \mathrm{kA} \mathrm{SC}$ supply and two quadrant operation is calculated. The result is presented in Fig. 4 in solid lines for the rectification (positive output voltage) and for the inversion modes.

The assumptions are: operation frequency of $50 \mathrm{~Hz}$, amplitude of the voltage generated by each transformer secondary coil of $2 \mathrm{~V}$, secondary impedance of the supply during commutation stages of $3.2 \mathrm{~m} \Omega$, time to activate the switch recovery in the inversion mode of $1 \mathrm{~ms}$ (solid line) and of $0 \mathrm{~ms}$ (dashed line), theoretical value of the converter maximum current of $2.5 \mathrm{kA}$.

A horizontal dashed line in Fig. 4 shows the ideal output characteristic of the supply in the rectification mode. A further improvement of the characteristic can be achieved when a voltage regulator is introduced in the circuit [5].

Several tests of the full scale components of the SC power supply described here, are on the way now. According to the programme, the system will be completed in the spring of 1994. The complete results of the investigations of the full scale SC supply described here will be presented elsewhere [10].

\section{CONCLUSIONS}

1. The concept and the configuration of a 1-2 $\mathrm{kA}$ superconducting power supply for a SC magnet are developed.

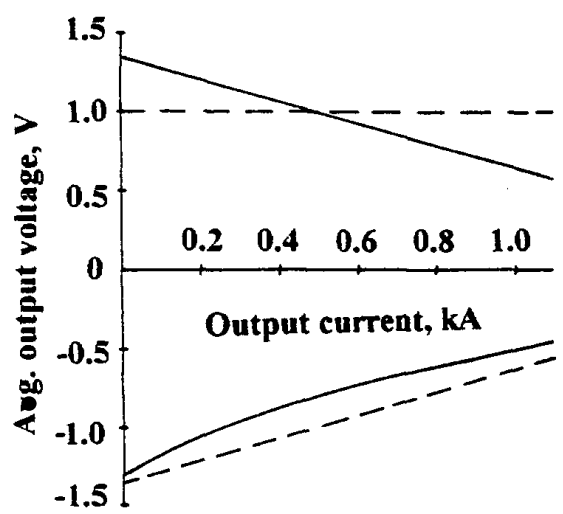

Fig. 4. Output characteristic of the SC power supply.
2. A new reliable and safe protection system (based on a 'cold' mechanical switch) enables the recovery of any superconducting element of the supply in the case of a quench without disturbing the magnet operation.

3. It is expected, that this device in combination with a semiconducting power supply provides an excellent electrical powering system for the separator magnet with an efficiency exceeding $\mathbf{9 8 \%}$.

\section{ACKNOWLEDGMENT}

This work is in the framework of the UT-IED collaboration. The authors thank their colleagues from the Applied Superconductivity Centre (UT) and from the Laboratory of Superconducting Converters (IED) for their assistance.

\section{REFERENCES}

[1] J. MoCarthy, and C.C. Smith ,"Power supply design for superconducting magnet applications", Superconducting Industry, pp. 22-27, Spring 1992.

[2] J. Sikkenga, H.H.J. ten Kate, A full scale superconducting rectifier for powering an MRI magnet. YEEE Trans. on Magn, Vol. 25, pp. 1819-1822, 1989.

[3] S.N. Afanasiev, et al., "Design of drum separator with superconducting magnet system", paper to be presented at this Conference.

[4] O.A. Shevchenko, G.B.J. Mulder, H.H.J. ten Kate, H.J.G. Krooshoop, and N.V. Markovsky, Development of a $50-60 \mathrm{~Hz}$ thermally switched superconducting rectifier, IEEE Trans. on Magn., Vol. 3, pp. 590-593, 1993.

[5] O.A. Shevchenko, H.H.J. ten Kate, H.J.G. Krooshoop, and N.V.Markovsky, "Operation modes of a $50-60 \mathrm{~Hz}$ superconducting converter", in press (paper presented at CEC"93, Albuquerque, USA, July 12-16, 1993).

[6] Strip-wound cut cores. VAC Publication, Vacuumschmelze GMBH, Hanau, $1987,96 \mathrm{p}$.

[7] O.A. Shevchenko, G.B.J. Mulder, N.Y. Markovsky, and H.H.J. ten Kate, "NbTi foil thermally controlled switches for superconducting converters with operation frequency up to $50 \mathrm{~Hz}$. Part I: experiment. Cryogenics (ICEC-14 Supplement) vol. 32, pp. 447-450, 1992.

[8] H.H.J. ten Kate, B. ten Haken, and L.J.M. van de Klundert, "An experimental mechanical switch for $3 \mathrm{kA}$ driven by superconducting coils. Adv. in Cryog. Engineering. Vol. 31, pp. 243-249, 1986.

[9] M.A. Fedorovsky, I.B. Djak, N.V. Markovsky, L.T. Jatsenko, G.M.Varsky, V.N. Sobolev, "Preliminary tests of SC power source for concentrator SC magnet system", unpublished, the paper PDE 07 to be presented at EUCAS'93, October 4-8, 1993, Gottingen, Germany.

[10] O.A. Shevchenko, H.H.J. ten Kate, H.J.G. Krooshoop, and M.A.Fedorovsky, "Operation of a new $50-60 \mathrm{~Hz}$ superconducting power supply for $1 \mathrm{kA}$ DC magnet", unpublished, the paper to be presented at ASC'94, October 20-24, 1994, Boston, USA 